InterAção | 37

\title{
HACIA EL NUEVO PARADIGMA ÁRABE
}

\author{
Francisco J. Berenguer Hernández \\ Teniente Coronel DEM \\ Analista Principal IEEE
}

\section{Resumen}

A lo largo de 2011 se ha comenzado a perfilar el cambio de modelo de Estado árabe que probablemente se generalizará durante los próximos años. Va a ser un tiempo tanto de riesgos como de oportunidades, en el que probablemente el ámbito mediterráneo sufrirá cambios profundos que tendrán implicaciones en el campo de la seguridad. El apoyo y asesoramiento occidental a los procesos revolucionarios es imprescindible, pero debe de mantenerse vigilante sobre posibles desviaciones que pongan en riesgo tanto las ansias de libertad y justicia social de los como la seguridad en el ámbito internacional y muy especialmente en el espacio mediterráneo.

Palabras clave: Estado árabe, primaveras árabes, seguridad en el Mediterráneo, islamismo.

\section{Abstract}

Throughout 2011 the arab State model has begun to change. It may be a generalized trend in the coming years. It will be a time of both risks and opportunities while profound changes will probably 
arrive around the Mediterranean in the field of security. The western countries advice and support to the revolutionary processes is essential, but those nations must remain vigilant on possible deviations that endanger both the desire for freedom and social justice as well as security in the international arena and especially in the Mediterranean area.

Keywords: Arab State, Arab Spring, security in the Mediterranean, islamism.

\section{El Principio del nuevo modelo}

En prácticamente un año transcurrido desde el inicio en Túnez de los procesos revolucionarios en numerosos países árabes obliga, en cierto modo, a reflexionar sobre lo sucedido en el convulso y recientemente finalizado 2011. Pero desde luego no desde la perspectiva de un ciclo finalizado, sino muy al contrario, desde el convencimiento de que en estos doce meses transcurridos se han cimentado los pilares de unos acontecimientos que van a ser transcendentes en el panorama estratégico de las próximas décadas.

Efectivamente el proceso de cambio no ha hecho más que empezar, hasta el punto de que de lo único que podemos dar testimonio en estos momentos es de la finalización del viejo paradigma del mundo árabe. Bien a través de reformas constitucionales o concesiones más o menos amplias que amplían las libertades y representatividad de los ciudadanos, bien por medio de insurrecciones armadas, lo cierto es que el panorama político del mundo árabe con el que se 
inicia 2012 difiere radicalmente de aquél con el que se cerró el tan cercano 2010.

Como consecuencia de ese conjunto de procesos, con sus realidades nacionales distintas, surge en cambio un modelo para cada Estado que presenta algunas características comunes, hasta donde puede en estos momentos vislumbrarse, la más importante de las cuales es el liderazgo político de los partidos islamistas. En consecuencia, el viejo modelo constituido por regímenes que presentaban un amplio abanico, desde sistemas parlamentarios tutelados y no plenamente representativos hasta dictaduras de carácter auténticamente tiránico, surgidos en gran medida del proceso de descolonización pero paradójicamente en buenas relaciones con Occidente, principalmente debido a su papel como muro de contención y represión del activismo islámico y el terrorismo de él originado, simplemente ha prescrito.

En su lugar, a esta cierta homogeneidad del mundo árabe está sucediendo paso a paso un nuevo modelo que se presenta también relativamente similar en numerosas naciones. Está constituido por regímenes plenamente democráticos, o al menos mucho más de lo que lo eran anteriormente, en los que la opción que representa al islamismo político se ha impuesto ya en las primeras elecciones, como es el caso de Túnez o Marruecos, está en camino de imponerse como en Egipto o Libia, o se impondrá tras el inevitable fin del régimen alauí de Siria. Está en consecuencia en camino un escenario constituido por un mundo árabe con gobiernos de mayoría islamista suní, que se unen al ya dilatado ejemplo en la misma dirección que representa Turquía, con los que va a ser necesario coexistir del mismo modo que se ha hecho hasta ahora con los antiguos regímenes, tratando de equilibrar 
40 | InterAção

los encuentros y desencuentros que sin duda vendrán con el objetivo de preservar la paz y la prosperidad de todos.

\section{Primeros indicios del nuevo orden}

Como ya sucediera en el comienzo de las revueltas, el mejor indicador de lo que está sucediendo es Túnez. Debido a su más temprano inicio y al desarrollo en gran medida ejemplar del proceso que está viendo el país, los acontecimientos tunecinos marcan la pauta y resultan en buena medida indicativos de lo que puede suceder en otras naciones cuyos procesos revolucionarios se encuentran en fases más tempranas.

La amplia victoria en las elecciones celebradas en el pasado mes de octubre del partido Ennahda, plenamente enmarcado en la corriente denominada en la abundante literatura generada como islamista moderada, se debe principalmente a dos causas convergentes. Una de ellas esencial y de carácter social, mientras que la segunda es más instrumental pero determinante sobre todo en estos primeros tiempos de funcionamiento del nuevo régimen. En el fondo de la cuestión se encuentra una realidad que va a tener vigencia muy probablemente en un período considerable de tiempo, que no es otra que la orientación islamista de un sector muy importante de la población. A pesar de que Túnez cuenta con los mejores índices de educación y preparación de su población en la zona, de un modo paralelo a la creciente incapacidad de satisfacer las necesidades y demandas de la población del régimen del derrocado presidente Zine El Abidine Ben Ali, los servicios sociales sustitutivos de los que corresponderían 
al Estado prestados por las organizaciones religiosas islamistas, unidos a una eficaz propaganda encargada de explotar esta circunstancia, han conseguido un crecimiento sostenido del islamismo político en el país. Sobre todo en aquellas zonas menos evolucionadas donde cubrir las necesidades primarias del día a día pesan bastante más que los debates, la teoría política o las ideologías de cualquier cuño. A los islamistas les ha bastado con aflorar a la superficie constituidos en partido político para tener un amplio apoyo electoral, sostenidos por una organización disciplinada, estructurada y experimentada, preexistente a la caída del antiguo régimen y el proceso electoral.

Además las características propias de cualquier régimen de partido único, como el establecido en Túnez en torno a la Reagrupación Constitucional Democrática de Ben Ali, han impedido el desarrollo de agrupaciones políticas de orientación distinta a la islamista a las que estas primeras elecciones han sorprendido divididos, en fase de constitución y consolidación. Demasiado "verdes" y con escaso calado popular en resumen. El resultado de la unión de ambos factores, en unas elecciones calificadas por la misión de observación de la Unión Europea como limpias y transparentes, ha sido el triunfo islamista.

Lo sucedido en Túnez se está repitiendo y muy probablemente lo va a hacer aún más en el futuro inmediato en otros países por la sencilla razón de que las dos razones expuestas en los párrafos anteriores, en mayor o menor medida, concurren igualmente en ellos. Evidentemente las generalizaciones hacen caer inevitablemente en el error, y las diferencias de los procesos emprendidos por ejemplo en Marruecos y en Libia, que se encuentran en extremos opuestos del abanico de sucesos experimentados en el mundo árabe a lo largo de 


\section{2 | InterAção}

2011, son inmensas. Pero el triunfo del marroquí Justicia y Desarrollo y el que probablemente obtendrán las opciones islamistas libias, o los Hermanos Musulmanes en Egipto, se corresponden en el fondo con causas muy similares. E incluso en algunos casos incrementadas en su intensidad, como puede ser el caso del ámbito rural egipcio, $y$ el consecuente apoyo incluso a un islamismo menos moderado como es el caso de los salafistas de Al Nour. Este es el principal motivo por el que los partidos islamistas están impulsando en todos los procesos la celebración de elecciones a la mayor brevedad, ya que son muy conscientes de la ventaja que tienen en este momento y de que la organización de los partidos no islamistas no hará sino mejorar con el paso de los meses.

El vigor de los avances islamistas ha empezado a manifestarse incluso en un país relativamente alejado hasta la fecha del torbellino generado alrededor de sus fronteras. Hasta ahora participante en la coalición de gobierno que sostiene al presidente Buteflika, la Alianza Presidencial, el Movimiento para la Sociedad y la Paz argelino, representante político del islamismo moderado en este país, acaba de anunciar su pase a la oposición con el evidente objetivo de presentarse a las elecciones que tendrán lugar en la próxima primavera. Su líder Bouguerra Soltani implícitamente ha dado por concluida la reconciliación nacional tras la sangrienta guerra civil de los años noventa, y considera llegado el momento de optar al poder en unas elecciones libres y transparentes. Queda por ver si en los argelinos tendrá más influencia el temor a una nueva victoria islamista en las urnas, hecho que sin duda ha contribuido a mantener a Argelia relativamente apartada de los procesos revolucionarios, o si por el contrario la pu- 
janza islamista de sus vecinos y correligionarios tiene un efecto de contagio, alcanzando entre el 35 y el 40\% de los votos como parecen indicar los pronósticos.

En lo que respecta a la situación de Siria, la revuelta contra el régimen y la violenta represión que éste ejerce no tiene un final fácil ni rápido, pero lo cierto es que en su desmesura el régimen ha acabado perdiendo la práctica totalidad de los apoyos exteriores de los que disfrutaba. Consentidas las sanciones por Rusia y China, abandonado el apoyo del que una vez disfrutó desde el Golfo y con su principal valedor Irán inmerso en sus propios problemas derivados del pulso a la comunidad internacional que mantiene debido a la no cancelación de su programa nuclear, el final de la dinastía Assad parece inevitable. Aunque posiblemente no inminente, porque la capacidad represiva del régimen sigue siendo muy superior a la de respuesta tanto política como militar de la oposición, que apenas comienza a vertebrarse.

El apoyo exterior a dicha oposición, posiblemente enmarcada en una dimensión mayor, con Irán y su "media luna Chî́” como damnificado colateral, puede verse incrementado paulatinamente, mientras que el enrocamiento del régimen en la represión violenta y desproporcionada no hará sino incrementar la sensibilidad y simpatía hacia los opositores. Si el régimen sirio cae, lo que en estos momentos parece inevitable, el proceso democrático resultará en un panorama similar al de sus países hermanos, con un parlamento con fuerte presencia del islamismo suní representado por la rama siria de los Hermanos Musulmanes. Como ya se explicó en un documento de análisis anterior esto supondría un cambio cualitativo en las relaciones de poder en Oriente Medio. 
44 | InterAção

Pero quizás el mayor indicio de que un cambio mayor está en marcha en la región es la actitud adoptada por Hamás. Convencidos del cese del apoyo sirio, al menos en los términos hasta ahora establecidos, y en consecuencia del obtenido de Irán, ha decidido tornar su posición hacia un pragmatismo del que hasta ahora no había hecho gala. La aceptación de un estado Palestino de acuerdo con las fronteras anteriores a la Guerra de los Seis días por parte de su líder Jaled Meshal, su anunciado retorno a Jordania para entrevistarse con el monarca jordano, o la visita a Estambul de su segundo, Ismael Haniya, evidencian una nueva estrategia que permitan a Hamás la vuelta a su entorno natural, alejándose de la circunstancial y operativa alianza que ha mantenido con el Irán chií y su aliado sirio. La reconciliación definitiva con Al-Fatah y el acercamiento a las posiciones políticas sostenidas por los Hermanos Musulmanes será la baza que Hamás intentará jugar en las elecciones palestinas fruto de este cambio y reconciliación.

\section{Aspectos positivos del Islamismo en el ámbito Árabe}

Como todas las situaciones, sean nuevas o no, el establecimiento de gobiernos islamistas en la mayoría de las naciones árabes, ofrece al menos a priori dos caras, con aspectos positivos y negativos, aunque es necesario subrayar el hecho de que esta nueva etapa de la historia árabe sólo está comenzando a escribirse.

En el lado positivo de la balanza hay que destacar la posible disminución o erradicación de las prácticas de corrupción de los antiguos regímenes. Posiblemente uno de los factores que mayor 
hartazgo ha ido reuniendo en los ciudadanos, el islamismo, debido a su vertiente ética y de mayor pureza en el comportamiento y las costumbres, presenta una esperanza real de que la endémica corrupción, tanto política como económica, sea erradicada de estas naciones, situándose en una escala de normalidad similar al de otras naciones de otros ámbitos geográficos y culturales. En este aspecto el proceso electoral desarrollado en Túnez, transparente, pacífico e irreprochable, es un ejemplo esperanzador a seguir.

Por supuesto hay que añadir los aspectos relacionados con el ejercicio de un sistema planamente democrático, donde los poderes del Estado y las Instituciones sean un reflejo mucho más cercano de la sociedad de la que emanan, sin olvidar aspectos tan esenciales como la seguridad jurídica, la libertad de expresión, etc, negados sistemáticamente por los antiguos regímenes.

Otro aspecto en el que pueden experimentarse mejoras sustanciales es en el posible aumento de un cierto sentido de universalidad panárabe, alimentada por la proximidad ideológica de los gobiernos, que sirva para disminuir el fuerte nacionalismo postindependentista, siempre presente en los sistemas políticos derribados. De este modo se mejorarían las expectativas de la tan necesaria integración sur-sur, muy deficiente en estos momentos.

En cuanto a la integración norte-sur paradójicamente muy superior, tan importante para Europa en general y España en particular, no tiene por qué verse perjudicada, como demuestra la larga convivencia con países como Arabia saudí y las monarquías del Golfo, que desde una óptica tan distinta a la de Occidente, están en cambio perfectamente imbricados en la comunidad internacional. $\mathrm{O}$, por su- 
46 | InterAção

puesto el caso turco.

Pero quizás el aspecto más positivo pueda ser el enfrentamiento de los nuevos gobiernos islamistas tanto a la realidad del ejercicio del poder en su propio país como a la de las relaciones internacionales. Siempre situados hasta cierto punto en la demagogia que pueden permitirse los que son conscientes de que no tendrán que asumir las responsabilidades de gobierno, comienza a ser hora de reconducir el discurso y las ambiciones islamistas a través de los cauces democráticos, limitados por los preceptos constitucionales, haciendo más difícil la argumentación de los sectores radicales y antidemocráticos. El ejercicio del poder es uno de las mayores curas de realismo que existen, tal y como muchos mandatarios han experimentado en sus propias carnes. El contacto con las instituciones internacionales, la economía real y los gobiernos extranjeros con sus intereses y sensibilidades, templa inevitablemente a los más fuertemente ideologizados.

En consecuencia, durante estas primeras legislaturas, el ejercicio del poder mostrará a la población si esta opción política, perseguida por unos e idealizada por otros antaño, es una opción real de mejora de las condiciones de vida del ciudadano medio o si, por el contrario, focaliza sus políticas en aspectos doctrinales que no logren satisfacer las ansias de mejora de la calidad de vida de la población, perdiendo entonces parte del apoyo mayoritario del que ahora gozan.

Finalmente no hay que olvidar que fue durante el largo mandato de los gobiernos corruptos y autoritarios cuando se produjo principalmente el proceso de radicalización de un sector de la población, llegando en algunos casos al ejercicio del terrorismo. Dichos gobiernos fueron en buena medida causantes de ese proceso, al mismo tiem- 
po que lo reprimían. Occidente durante años ha preferido tener en cuenta más este segundo aspecto que el primero, pero no cabe duda que en conjunto la cuenta de resultados de estos dirigentes ya apartados del poder ha sido negativa. Los gobiernos autoritarios hicieron germinar en su seno el radicalismo más extremo y el terrorismo, por lo que el nuevo sistema que ahora comienza a articularse merece una oportunidad y difícilmente puede empeorar el balance interno y externo de aquéllos. Sin olvidar que de resultar exitosos los cambios en marcha contribuirán sin duda a la desactivación de la mayoría de los argumentos conducentes a la radicalización y al terrorismo.

\section{Riesgos de la expansión estatal del Islamismo}

Sería absurdo no obstante caer en la tentación de un exagerado buenismo y obviar los riesgos que se esconden detrás de las revoluciones en desarrollo y de otras que probablemente vendrán en varios países. Hay que tener en cuenta que las revueltas se han generado por causas que tienen más que ver con la falta de libertades, la corrupción, la injusticia social, el estallido demográfico árabe, la expansión de las comunicaciones y el conocimiento, etc... que con principios ideológicos. Fueron lanzadas y encabezadas por sectores sociales en general alejados del islamismo, pero sin embargo tras las elecciones éstos parecen ser los principales beneficiarios.

Es dudoso que el islamismo sea capaz de satisfacer todas las demandas de los manifestantes, antes bien parece apuntar en dirección contraria a muchas de las reivindicaciones, pudiendo crearse así el germen de una nueva insatisfacción y una división de la sociedad 
en islamistas y antiislamistas. Un buen ejemplo de este problema es la petición de suspensión temporal de las elecciones egipcias por una nueva oleada de manifestantes ante las condiciones que atraviesa el país, que han contado con la inmediata oposición de Hermanos $\mathrm{Mu}-$ sulmanes al sentirse principales beneficiarios del proceso electoral.

No hay que ocultar tampoco la abundancia en todos los países implicados de declaraciones preocupantes de líderes religiosos respecto a aspectos fundamentales. Sin ir más lejos Ahmed el Tayeb, conocido líder religioso egipcio, consideró las protestas de la comunidad internacional por los actos violentos ejecutados contra la minoría copta como una injerencia en los asuntos internos de Egipto. U otras varias referidas a las obligaciones "islámicas" de los visitantes extranjeros, lo que supondría de hecho la creación en estos países de santuarios islamistas, con la obligatoria práctica de sus preceptos más allá del ejercicio de las normas de cortesía intercultural que con toda naturalidad se han venido observando todos estos años, lo que provocaría sin duda la radical disminución del turismo, fuente de ingresos irrenunciable para países como Túnez o Egipto. Aunque es cierto que estas declaraciones pueden ser interpretadas en el contexto actual en clave electoralista, no es menos cierto que de ser así presentaría una lectura de la opinión pública preocupante, pues significaría que “cuanto más radical más popular".

Por otra parte abundan en mayor proporción los mensajes de carácter moderado e integrador, producto en gran medida de la necesidad de no alarmar a occidente y a amplios sectores de sus propias sociedades. Queda por ver si esa moderación es compartida por todos los sectores del islamismo político o, por el contrario, se camu- 
flan actualmente en su seno elementos antidemocráticos que aspiran a alcanzar una islamización forzada e intransigente de sus respectivos países, lo que supondría el fracaso de los procesos revolucionarios y en definitiva el cambio de una tiranía por otra a medio plazo.

$\mathrm{El}$ enfrentamiento entre ambas opciones puede visualizarse en las diferencias que separan a salafistas y Hermanos Musulmanes en Egipto en aspectos esenciales de la vida nacional, como la economía, la aceptación de las minorías, especialmente religiosas, con el consiguiente peligro de la creación de ciudadanos de "segunda" (cristianos, judíos, sufíes, chiíes), la política exterior, los derechos individuales del ciudadano o el ya referido turismo.

Dentro del normal desarrollo de la vida parlamentaria, la hipotética constitución en sucesivas legislaturas de partidos islamistas menos moderados, como Gama'a Islamiya, los citados salafistas u otros equivalentes en las distintas naciones, en partidos bisagra necesarios para establecer coaliciones de gobierno o asegurar la estabilidad, conseguiría sucesivamente arrancar concesiones a sus postulados contribuyendo a condicionar las políticas de los partidos gobernantes, en un mecanismo similar al que viene sucediendo en otras naciones con formaciones minoritarias de corte regionalista, ecologista, o de extrema derecha, por ejemplo.

En el mismo contexto parlamentario, y en relación con el punto anterior, puede estar presente el interesado enfrentamiento de las iniciativas de la oposición con el dogma religioso como forma de invalidación de dicha oposición, desvirtuando el juego democrático. También en esta órbita se sitúa la tentación de "tomar la calle", utilizando a las masas de correligionarios, principalmente tras las ora- 
50 | InterAção

ciones de los viernes en períodos y fechas de especial sensibilidad religiosa, para invalidar el papel de la oposición, deslegitimándola. Nos enfrentaríamos en este indeseable caso con la utilización instrumental del sistema democrático para su destrucción, provocando el establecimiento de teocracias, lo que supondría el total fracaso de los procesos revolucionarios y una alteración de las condiciones de seguridad de nuestro entorno más inmediato.

Estas alteraciones podrían presentar muchas facetas, pero una de las más significativas podría ser el apoyo a la intensificación del proselitismo islamista radical en Occidente, ya preocupante en diversos países europeos, dificultando el proceso de integración de las poblaciones musulmanas y favoreciendo el ya iniciado auge de los partidos ultranacionalistas y xenófobos europeos. Sin olvidar un recrudecimiento del conflicto árabe-israelí, al sustituir gobiernos dotados de un cierto pragmatismo por otros muy fuertemente ideologizados.

Por último, pero no por ello de gran importancia, entre los riesgos de la islamización de los gobiernos árabes no debe de olvidarse el referido al posible retroceso en la condición de la mujer. Ésta ha experimentado notables avances en muchos países árabes y ha sido protagonista en buena medida de la revolución, pero en caso del triunfo de opciones menos moderadas puede ser la principal damnificada. Las intimidatorias pruebas de virginidad practicadas a manifestantes egipcias, o la presentación de candidatas salafistas por medio de fotos de sus maridos en la cartelería electoral ante la imposibilidad de mostrar su rostro ni aún velado, no son buenos indicios, lo que está llevando a la creación de organizaciones de defensa de los derechos de la mujer por parte de activistas temerosas de esta posibilidad, como es 
InterAção | 51

el Frente 24 de Octubre tunecino.

En definitiva un panorama lleno de luces y sombras que augura un apasionante proceso constituyente en la mayoría de los países afectados por la ola de cambios.

\section{El papel de la Orilla Norte del Mediterrâneo}

En gran medida la postura de Occidente, representado por las posiciones oficiales de la UE y de Estados Unidos, ya ha sido definida y se ha puesto en práctica. El apoyo inequívoco a los procesos revolucionarios ha pasado pronto de las palabras a los hechos, como demuestran los apoyos económicos y de asesoramiento que en estos momentos se están aplicando, por lo que no cabe hablar sino de una política proactiva de apoyo y ayuda al mejor desarrollo de los procesos, lo que constituye una postura coherente en lo ideológico y además preñada de pragmatismo.

En este sentido, parece que se han conseguido, al menos inicialmente, eliminar prejuicios y evitar posicionamientos hostiles previos al desarrollo de los acontecimientos, a pesar de que los dictadores acosados no dudaron en su momento de agitar el fantasma del temor al islamismo y al terrorismo yihadista como parte y promotor de las revueltas, patrón que vuelve a repetirse meses más tarde por parte del régimen del presidente sirio $\mathrm{Al}$ Assad, mientras que los atentados terroristas en Damasco, coincidentes con la presencia del equipo de observadores de la Liga Árabe, son sospechosamente oportunos, sin que hasta el momento haya sido posible determinar ni los autores ni la causa a la que sirven. 
Pero este apoyo, necesario y positivo, no debe de dejar de ser ciego. La vigilancia sobre aspectos fundamentales en el desarrollo de los procesos políticos es igualmente imprescindible, principalmente en los que se refieren al respeto de derechos fundamentales de los ciudadanos, pluralidad y transparencia en los procesos electorales y respeto a las leyes tanto en su dimensión interna como en el ámbito internacional. Sucesos como la ejecución extrajudicial de Gadafi, las referidas prácticas intimidatorias de los militares egipcios contra mujeres participantes en las recientes manifestaciones o la visita a Trípoli del presidente sudanés Omar al Bashir, a pesar de estar perseguido por el Tribunal Penal Internacional, por poner sólo algunos ejemplos, no van en la buena dirección que se ha de exigir a las nuevas autoridades.

Aunque hay que reconocer que en todo proceso revolucionario se producen desajustes y excesos, éstos no deben de convertirse en la norma, y mucho menos instalarse en los nuevos regímenes como prácticas aceptadas y habituales. En estos términos el papel a jugar por la UE, en buenas relaciones con todos los países afectados, debe de ser determinante. Para ello debe de observar y apoyar los procesos, como está haciendo, pero también exigir que las nuevas autoridades, sean de la tendencia o el color que sean, no crucen ciertas líneas rojas, clara e inequívocamente establecidas, inaceptables para las sociedades occidentales y el conjunto de la comunidad internacional.

\section{CONCLUSIONES}

Vivimos evidentemente tiempos de cambio. A la retracción estratégica que está experimentando occidente, no sólo por motivos 
económicos por cierto, y la irrupción en el primer plano del panorama mundial de las potencias emergentes, con la relativamente reciente pero muy intensa implicación china en el contexto internacional, hay que sumar el cambio de modelo de Estado árabe que se ha comenzado a perfilar en 2011.

Aflora por tanto un tiempo tanto de riesgos como de oportunidades, en el que probablemente el ámbito mediterráneo sufrirá cambios profundos que tendrán implicaciones en el campo de la seguridad. Es necesario que las revoluciones triunfen y que el mundo árabe experimente en los próximos tiempos un gran salto adelante, demasiado postergado tras los procesos independentistas a lo largo del siglo XX.

Este salto no puede darse de espaldas a la realidad social árabe, que indudablemente ha experimentado en los últimos años una creciente islamización. Pero no puede darse tampoco a cualquier precio. El apoyo y asesoramiento occidental a los procesos revolucionarios y sus consecuencias políticas es imprescindible y muy positivo, pero debe de conjugarse con la observación y la vigilancia sobre posibles desviaciones que pongan en riesgo tanto las ansias de libertad y justicia social de los pueblos que están en proceso o han logrado librarse de gobernantes autoritarios y corruptos, como la seguridad en el ámbito internacional y muy especialmente en el espacio mediterráneo. 
54 | InterAção 